\title{
Identification of the Lineage Markers and Inhibition of $D A B 2$ in In Vitro Fertilized Porcine Embryos
}

\author{
Jong-Nam Oh ${ }^{1} \oplus$, Mingyun Lee ${ }^{1}$, Gyung Cheol Choe ${ }^{1}$, Dong-Kyung Lee ${ }^{1}$, Kwang-Hwan Choi ${ }^{1}$, \\ Seung-Hun $\mathrm{Kim}^{1}{ }^{\mathbb{D}}$, Jinsol Jeong ${ }^{1}$ and Chang-Kyu Lee ${ }^{1,2, *}$ \\ 1 Department of Agricultural Biotechnology, Animal Biotechnology Major and Research Institute for \\ Agriculture and Life Sciences, Seoul National University, Seoul 08826, Korea; ojn0505@snu.ac.kr (J.-N.O.); \\ mg1011811@snu.ac.kr (M.L.); epicurian@snu.ac.kr (G.C.C.); culi1039@snu.ac.kr (D.-K.L.); \\ ckh1122@snu.ac.kr (K.-H.C.); forevers122@snu.ac.kr (S.-H.K.); wlsthf0216@snu.ac.kr (J.J.) \\ 2 Institute of Green Bio Science and Technology, Seoul National University, Pyeongchang 25354, Korea \\ * Correspondence: leeck@snu.ac.kr
}

Received: 11 August 2020; Accepted: 29 September 2020; Published: 1 October 2020

\begin{abstract}
Specification of embryonic lineages is an important question in the field of early development. Numerous studies analyzed the expression patterns of the candidate transcripts and proteins in humans and mice and clearly determined the markers of each lineage. To overcome the limitations of human and mouse embryos, the expression of the marker transcripts in each cell has been investigated using in vivo embryos in pigs. In vitro produced embryos are more accessible, can be rapidly processed with low cost. Therefore, we analyzed the characteristics of lineage markers and the effects of the $D A B 2$ gene (trophectoderm marker) in in vitro fertilized porcine embryos. We investigated the expression levels of the marker genes during embryonic stages and distribution of the marker proteins was assayed in day 7 blastocysts. Then, the shRNA vectors were injected into the fertilized embryos and the differences in the marker transcripts were analyzed. Marker transcripts showed diverse patterns of expression, and each embryonic lineage could be identified with localization of marker proteins. In DAB2-shRNA vectors injected embryos, HNF4A and PDGFRA were upregulated. $D A B 2$ protein level was lower in shRNA-injected embryos without significant differences. Our results will contribute to understanding of the mechanisms of embryonic lineage specification in pigs.
\end{abstract}

Keywords: pig; embryo; lineage markers; DAB2

\section{Introduction}

Cells are continuously divided into diverse cell types starting from a single fertilized egg to the whole organism [1]. Early stage blastomeres have totipotency and select their fate between inner cell mass (ICM) and trophectoderm (TE) [2]. Cells in ICM separate into two lineages, epiblast (EPI) and primitive endoderm (Pri-Endo) [3]. Understanding this lineage specification provides clues to modulate the cell's fate. Various embryonic factors help the cells to decide their lineages in the vertebrates [4]. Eggs of frog and zebrafish already have molecular gradation at fertilization, and the gradation determined the position of the axis of the embryo [5]. In mammals, the trigger of segregation does not exist at the time of fertilization. In the case of mice, heterogeneity is observed starting from the four-cell stage; this asymmetry induces cell fate decisions at the early stages [6]. Models of the blastocyst (BL) formation have been suggested and molecules and signals that regulate the lineage specialization have been identified $[7,8]$.

Advanced techniques, e.g., RNA-seq, single cell-based analysis and genome-wide methylation profiling have been used to study embryo segregation. The dynamics of transcriptional factors were investigated by quantitative PCR (qPCR) in each embryonic cell [9]. Advanced imaging tools were 
used to determine detailed morphology of the BL visualize and distinguish each cell in an embryo in three dimensions (3D) [10]. Transcriptome profiles of embryonic cells have been examined by RNA-seq analysis in many mammalian species. Established lineage-specific genes were verified, and the balance of transcripts was suggested as a driving force of segregation in mice [11,12]. Three germ layers are distinguished clearly in the transcriptome and the marker genes were categorized based on the levels of transcripts in human embryos [13]. Some markers showed similar patterns to the mouse marker while other markers have completely different tendencies [14]. Single cell-based epigenetic studies monitor the changes in DNA-methylation in the early embryos. DNA-methylation is dynamic within the developmental stages, and the overall pattern is different between mouse and human $[15,16]$. Pigs have considerable physiological similarity to humans; thus, pigs can be used as a model to study early development $[17,18]$.

In addition to mouse and human models, single cell-based studies have been conducted in other species. The transition of expression of the marker genes was observed by transcriptome analysis in the bovine embryo [19]. In porcine in vivo embryo, lineage-specific characteristics were identified by single-cell analysis. Using single cell qPCR, stage- and lineage-specific genes were identified, and ICM/TE cells were sorted according to the patterns of the marker gene expression [20]. Cells were categorized into lineage groups based on the single cell RNA-seq, and it has been demonstrated that certain conventional lineage markers (e.g., CDX2 and TEAD4) do not correspond to markers detected in porcine embryos [21,22]. A number of studies have been investigating in vivo embryos; however, detailed information about in vitro fertilized (IVF) porcine embryos remains unavailable. Embryos can be produced from oocytes and sperm in the laboratory; thus, IVF has a number of advantages in accessibility including time and costs. Thus, to boost the lineage studies in pigs, characterization of the lineage markers is needed to be conducted in the IVF embryos.

Despite a number of similarities, early embryonic development, including TE segregation, shows considerable variability between species [23]. In mouse embryos, the YAP/TEAD4 signaling leads to cell segregation into TE through the CDX2 expression [24]. As a result of cell polarization, $C D X 2$ is responsible for the allocation of TE in the early embryo $[25,26]$. CDX2 is also essential in the polarization of porcine embryos and OCT4 inhibition [27]. In cattle, CDX2 is required for TE maintenance but does not repress OCT4 [28]. However, in pigs, single cell analysis based on qPCR and RNA-seq demonstrated that the expression levels of $C D X 2$ had no differences between the ICM and TE cells, whereas the $D A B 2$ gene was abundantly expressed in the TE cells $[20,21]$. The role of the $D A B 2$ gene has to be investigated to understand the lineage specialization of the porcine embryo.

In this study, we characterized in vitro-fertilized porcine embryos and investigated $D A B 2$ gene inhibition. Initially, we investigated the stage-specific expression patterns of the marker genes and relative distribution of the marker proteins in the BLs. The expression levels of the marker genes for TE, ICM, and Pri-Endo were measured in various embryonic stages (4-cell, morula, early BL, and late BL). Then, BLs on day 7 were immunostained using a two-step double staining method to verify the relative distribution of the marker proteins. Then, we injected the shRNA vectors into the fertilized eggs. After culture, the levels of the transcript and protein expression in the embryos with or without shRNA were compared by qPCR and immunostaining. The results will help to understand the lineage-related profiles of IVF embryos and the role of DAB2 in the development of preimplantation embryos.

\section{Results}

\subsection{Marker Gene Expression of IVF Embryos during Development and Distribution of Marker Proteins in Day 7 IVF Embryos}

Recent studies of porcine embryo had verified a number of common markers and discovered pig-specific lineage markers [20-22]. We have identified the trends of the marker gene expression in the porcine embryos (Figure 1A). Embryos in the 4-cell, morula, early BL, and late BL stages were used on days 2, 4, 5, and 7 of the culture, respectively. TE markers, including DAB2, GATA3, and CDX2, showed stage-specific differences. $D A B 2$ expression level was the highest in the early BL stage and 
was significantly decreased in the late BL stage compared with that in the morula and early BL stages. GATA3 was increased from the morula to early BL stages. CDX2 level was also increased and remained high until the late BL stage.

A
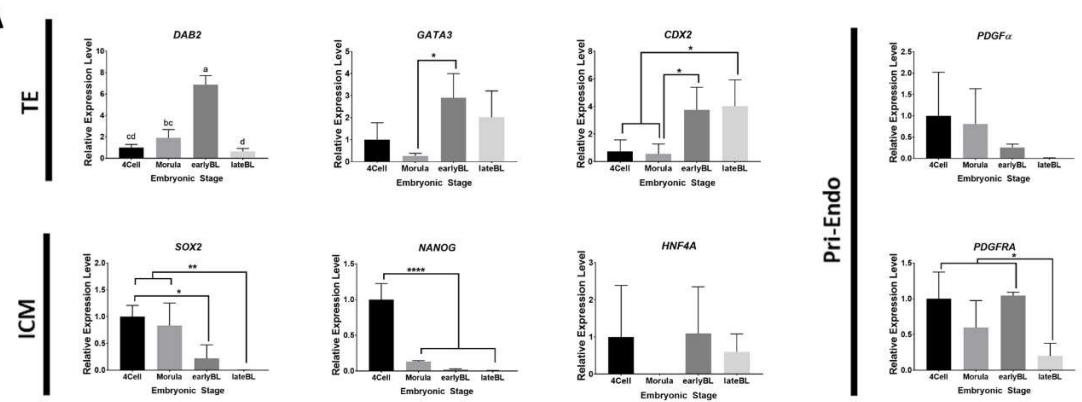

B
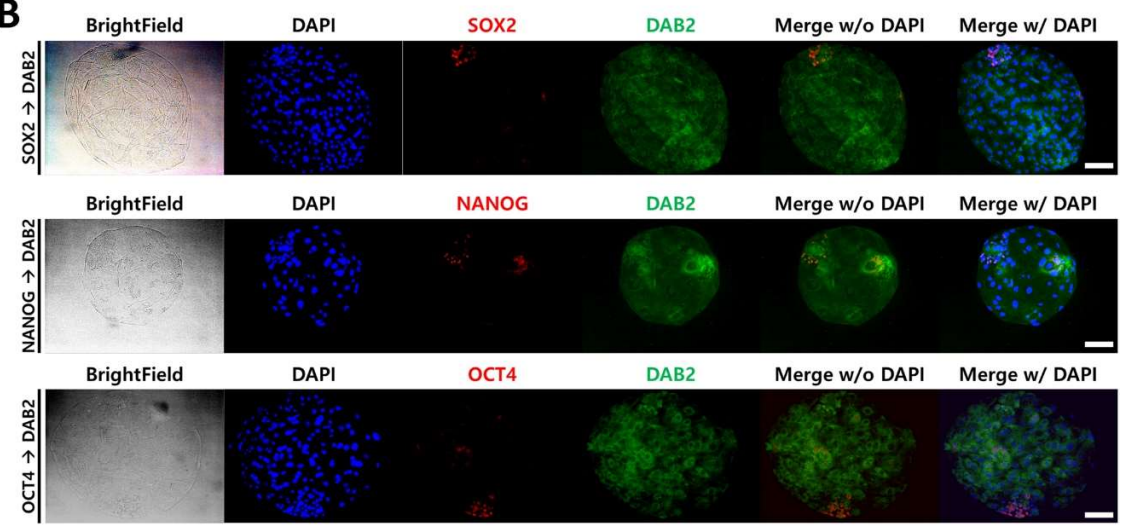

C
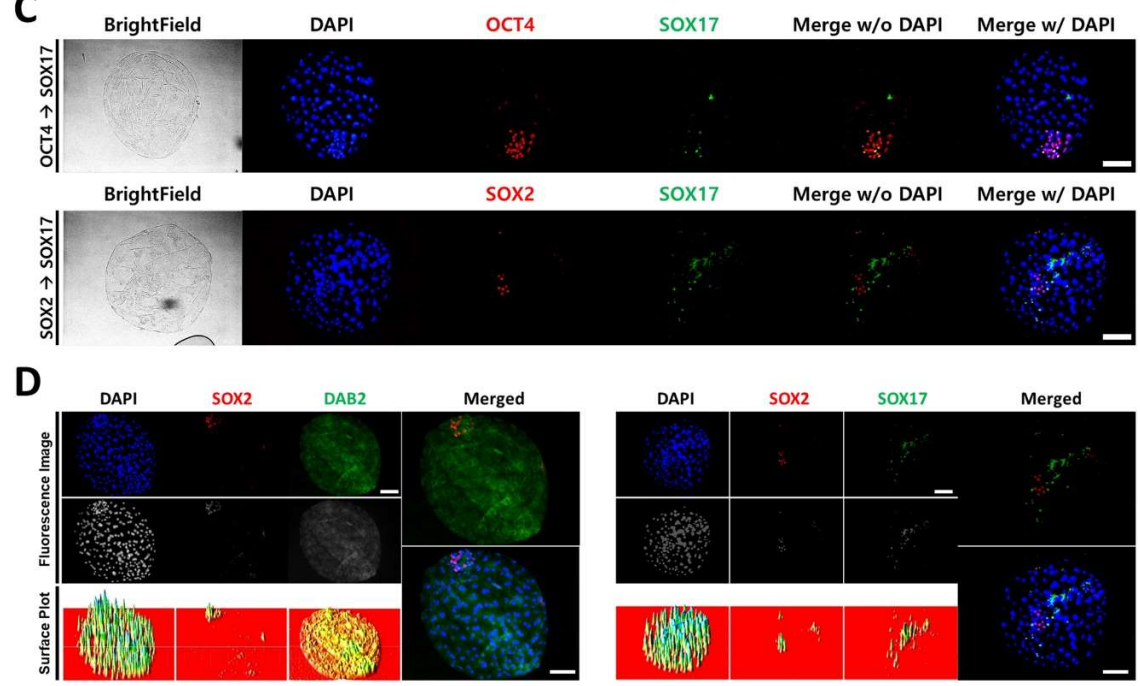

Figure 1. Marker mRNA levels in embryonic stages and marker protein distribution in day 7 blastocyst. (A) Expression levels of well-known lineage markers (Trophectoderm (TE); DAB2, GATA3, CDX2; Inner cell mass (ICM); SOX2, NANOG, HNF4A; Primitive endoderm (Pri-Endo); PDGF $\alpha$, PDGFRA) were measured in 4-cell, morula, early BL and late BL stages. Different letters and ${ }^{*}$ correspond to significant differences. $\left({ }^{*}: p<0.05,{ }^{* *}: p<0.01,{ }^{* * * *}: p<0.0001\right)$. (B), (C) and (D) Double immunostaining of day 7 IVF embryos. Images of bright field, DAPI and two lineage marker proteins are shown. Size marker corresponds to $100 \mu \mathrm{m}$. (B) SOX2, NANOG and OCT4 in combination with DAB2. (C) SOX2 and OCT4 in combination with SOX17. Size markers correspond to $100 \mu \mathrm{m}$. (D) Surface plot image of Figure 1B (SOX2 and DAB2) and 1C (SOX2 and SOX17). Higher peak in the surface plot corresponds to the higher signal on the image. Size marker corresponds to $100 \mu \mathrm{m}$. 
We examined the relative distribution of marker proteins in day 7 BLs. SOX2, NANOG, and OCT4 were expressed at the high levels in the nuclei; the nuclei were small and dense (Figure 1B). DAB2 was located in the cytoplasm of the cells; $D A B 2$ expression was relatively uniform in the whole BL (Figure 1C). Three ICM markers had different distribution (Figure 1D). SOX2- and SOX17-positive cells were exclusive to each other, and SOX17-positive cells were a part of the OCT4-expressing group of cells.

\subsection{Cloning of Vectors and Verification of the shRNA Expression Vectors}

To produce the shRNA expressing vector, candidate shRNA sequences containing sense-loop-antisense-5U were inserted on the U6 promoter site of pENTR.hU6hH1 (Figure 2A). We selected the clones with exact sequences. The plasmid vector that expresses the $D A B 2$ coding region was also constructed (Figure 2B).

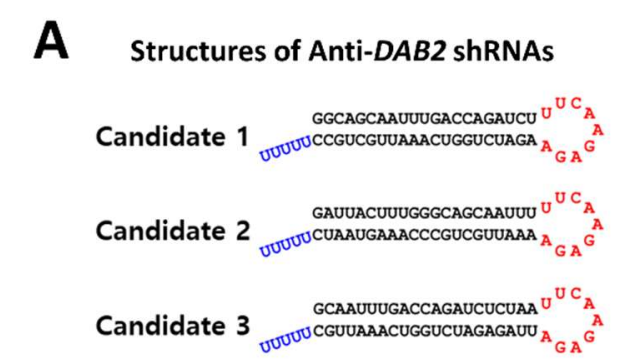

D

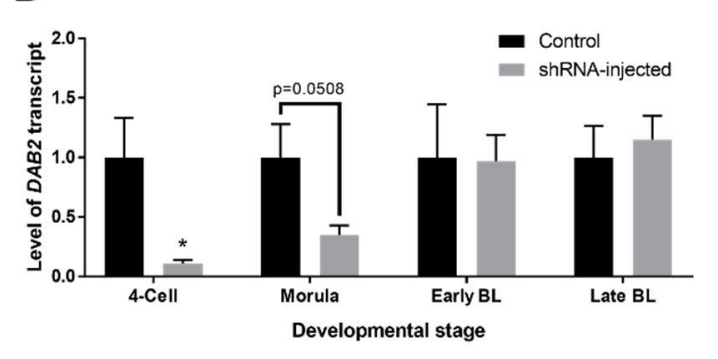

F

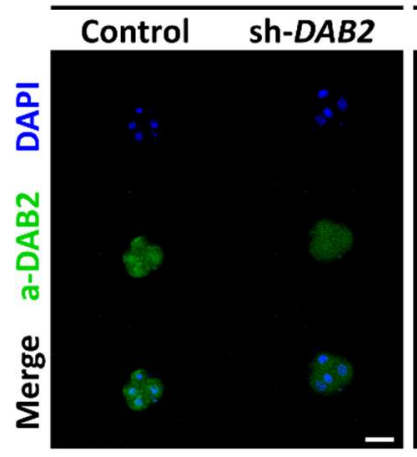

Morula
B

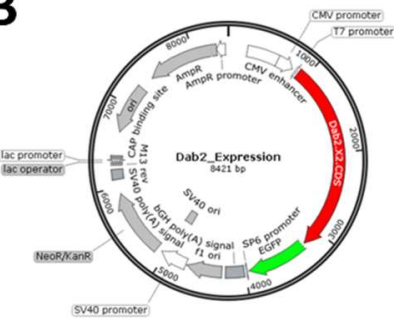

E
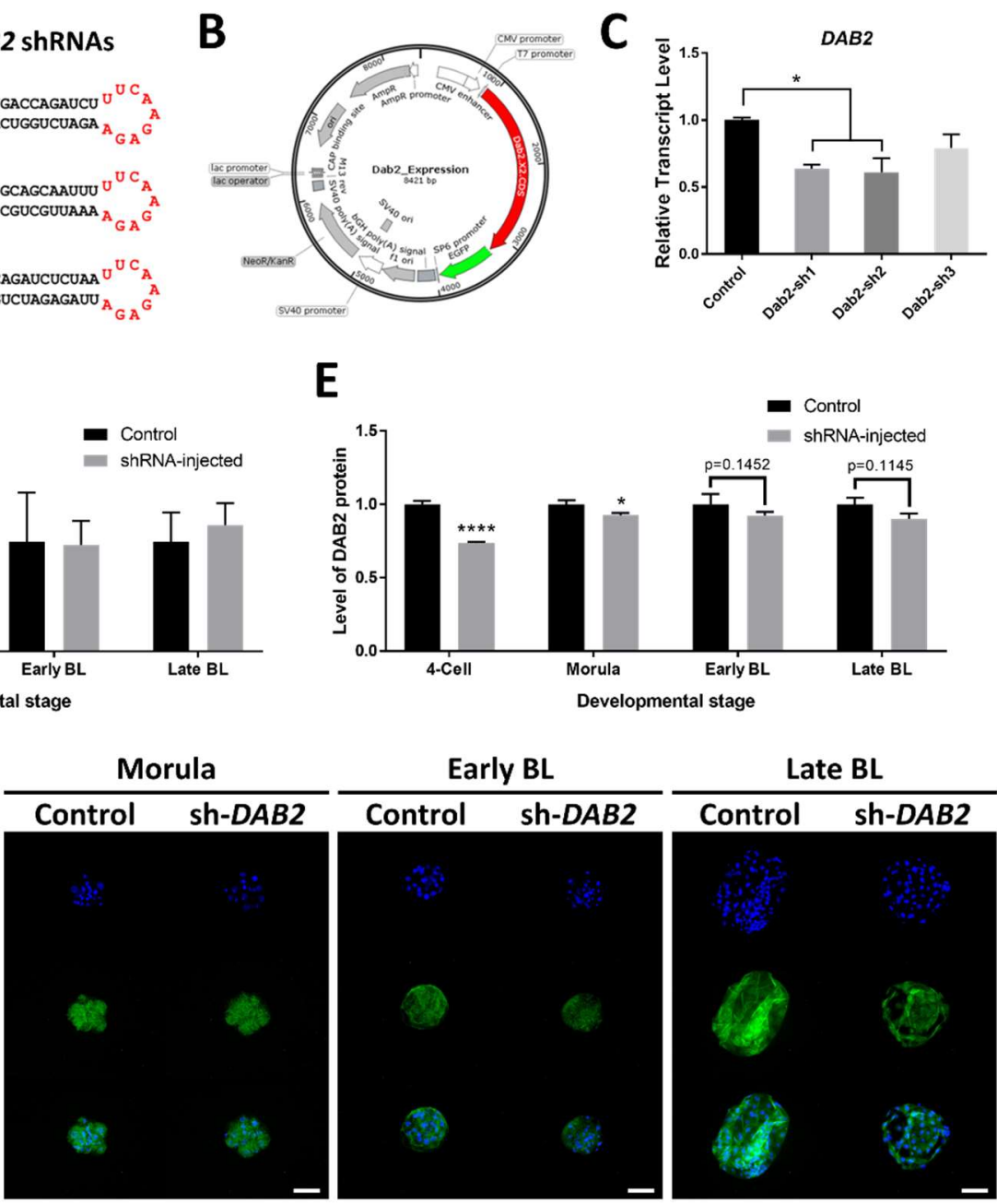

Early BL

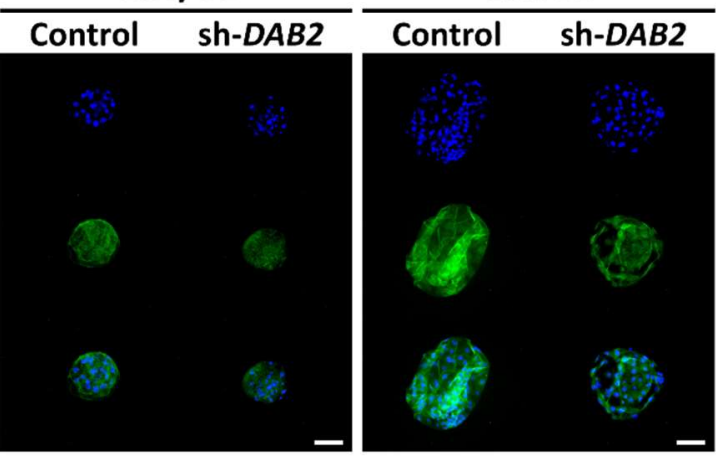

Figure 2. Vector information and verification of shRNA. (A) Expected shRNA structures of each candidate. (B) Plasmid map of the DAB2 coding region expression vector. (C) DAB2 transcript levels in the $\mathrm{pFF}$ cells transfected with shRNA vectors. (D) Relative level of $D A B 2$ transcript and (E) relative level of $D A B 2$ protein in 4-cells, morula, early blastocyst, and late blastocyst stages with or without shRNAs. (F) Immunocytochemistry images of $D A B 2$ protein in 4-cells, morula, early blastocyst, and late blastocyst stages with or without shRNAs. * corresponds to significant differences. $\left({ }^{*}: p<0.05\right.$, ****: $p<0.0001)$. Size makers correspond to $100 \mu \mathrm{m}$. 
For verification of the shRNA-expressing vectors, each candidate vector was transfected into the porcine fetal fibroblasts $(\mathrm{pFF})$ together with the $D A B 2$ gene expression vector and the cells were cultured for 3 days ( 1 day with and 2 days without DNA plus lipofectamine). Complementary DNA was synthesized from RNA extracted from cultured pFF. DAB2 mRNA level was low in candidates 1 and 2 but did not show significant changes in candidate 3 . Thus, a mixture of candidates 1 and 2 was subsequently used for embryo microinjection (Figure 2C).

To verify the effect of shRNAs in embryo, we injected vector mixture into fertilized embryos. The level of $D A B 2$ transcript was significantly low in 4-cells embryos with shRNAs and no significant difference was observed in following stages (Figure 2D). Morula with shRNAs showed lower level of $D A B 2$, but there was a lack of significant difference. In case of protein, $D A B 2$ level was low in 4-cells and morula stage embryos with shRNAs (Figure 2E). Representative images used to measure protein level of $D A B 2$ were shown in Figure 2F.

\subsection{Marker mRNA Expression and Protein Distribution in shRNA-Injected Embryos}

Verified vectors expressing anti-DAB2 shRNAs were microinjected into the IVF embryos. Empty vector with no shRNA sequence insertion was used as a control of microinjection. There were no significant differences in the cleavage rate on day 2 and no differences in the BL formation rate on day 7 (Figure 3A).

A
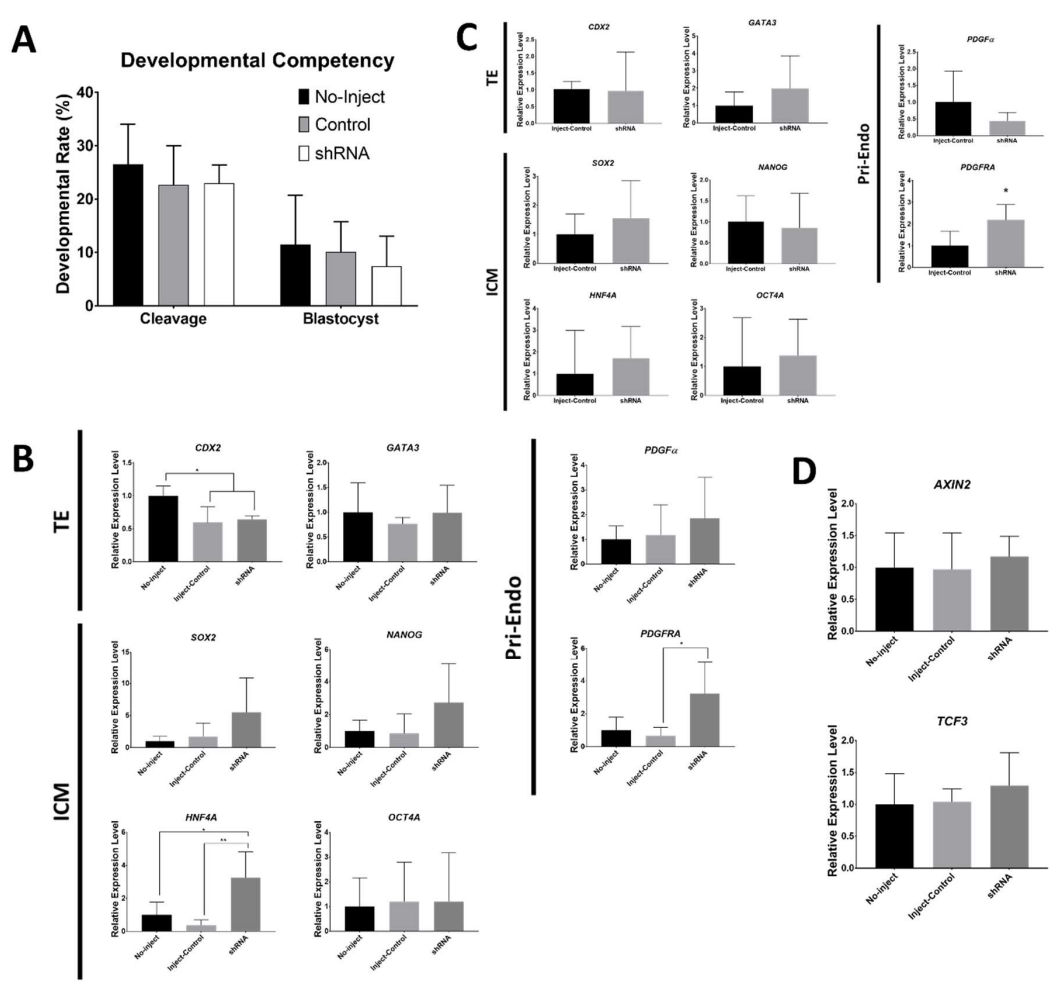

Figure 3. Analysis of embryos after microinjection of anti-Dab2 shRNA vector. No-inject; embryos without microinjection, Control; embryos that were injected with an empty vector without shRNA, shRNA; shRNA vector-injected embryos (1:1 mixture of candidate 1 and 2). (A) Development competency of embryos with or without microinjection. (B) Expression levels of marker mRNAs in day 7 embryos (Trophectoderm (TE); GATA3, CDX2; Inner cell mass (ICM); SOX2, NANOG, HNF4A; Primitive endoderm (Pri-Endo); PDGF $\alpha$, PDGFRA). (C) Expression levels of marker mRNAs in day 5 embryos (Trophectoderm; GATA3, CDX2; Inner cell mass; SOX2, NANOG, HNF4A, OCT4A; Primitive endoderm; PDGF $\alpha, P D G F R A$ ). (D) Expression levels of DAB2 target candidates (AXIN2 and TCF3) in day 7 embryos. ${ }^{*}$ corresponds to significant differences. $\left({ }^{*}: p<0.05,{ }^{* *}: p<0.01\right)$. 
We measured the mRNA expression levels of the marker genes in day 7 BLs with or without shRNA microinjection (Figure 3B). There were no significant differences between the BLs with and without the injection of the control vector in most of the genes. With regard to the TE markers, the level of CDX2 was lower in shRNA-injected embryos than that in embryos without the injection; however, the embryos injected with the control vector had a low level of CDX2. In the case of other TE markers, $D A B 2$ and GATA3 had no differences between the treatments. The expression levels of the ICM markers, SOX2, NANOG, and HNF4A, was the highest in shRNA-injected embryos. However, there was a significant difference in HNF4A. The level of a Pri-Endo marker, PDGFRA, was higher in the shRNA-injected samples than that in the samples injected with the control vector; however, there was no difference in the level of PDGF $\alpha$ expression

Expression levels of the marker genes were also quantified in the injected BLs on day 5 (Figure 3C) when the expression of $D A B 2$ is the highest during embryonic development (Figure 1A). The ICMand TE-specific genes did not have differences in the transcript levels. PDGFRA, a Pri-Endo marker, was increased in the samples injected with shRNAs. The levels of AXIN2 and TCF3 transcripts were measured in day 7 BLs to verify the downstream $D A B 2$ targets; however, no significant differences were observed (Figure 3D).

\section{Discussion}

The decision of cell fate with regard to cellular lineages is an autonomous process in the early embryo. The division of the cells based on cell fate is taking place inside of the embryo and requires specific triggers. These triggers and their mediators may be related to polarity within embryonic cells. Differences between the lineages have been investigated to identify a clear trigger of segregation [29]. Mammalian embryos have interspecies variability in lineage segregation [30]. The pig is an ideal animal model relevant to human application and information on lineage specification in pigs is important [31]. Moreover, in vivo and in vitro produced embryos have differences in a number of aspects [32,33]. Thus, the lineage segregation study of porcine IVF embryos is required. Therefore, we analyzed the stage-specific expression patterns of the marker genes and relative distribution of the marker proteins.

Triggers involved in the first segregation of ICM and TE should be present at least at the morula stage. Our results indicate that TE markers, including $D A B 2, G A T A 3$, and $C D X 2$, were not expressed in morula at the high levels. The expression levels of these three markers were increased during early BL (day 5). Because early BL already underwent ICM and TE, these genes may support maintenance or functional specification of the TE lineage. The transcription level of $D A B 2$ was significantly decreased during the transition from early to late BL; however, the other two genes were continuously expressed until the late BL stage. Apparently, DAB2 has a role in an earlier stage compared to the roles of GATA3 and CDX2. SOX2 and NANOG, the ICM markers, had the highest levels of transcription during the 4-cell stage. This result means that their expression may start with embryonic genome activation. The expression of SOX2 was sustained up until the morula stage and significantly decreased after the early BL stage. In the case of $N A N O G$, the level of the transcript was dramatically decreased starting from the morula stage. However, HNF4A had no significant difference within the embryonic stages. In brief, SOX2 and NANOG have stage-specific expression and decreasing trends during the embryonic development; the NANOG transcript was abundant in the earlier phases compared with the levels of SOX2. These two genes may be involved in the specialization of the ICM lineages. In humans and mice, Sox 2 and Nanog contribute to the maintenance characteristics of the cells derived from ICM of the embryos [34]. In the case of two Pri-Endo markers, the expression level of PDGF $\alpha$ showed a decreasing trend during embryonic development; however, there were no significant differences between stages. The level of the transcript of PDGFRA was significantly decreased during the late BL stage. In the mouse studies, PDGF signaling is essential for maintenance and expansion of the Pri-Endo lineage [35,36]. PDGFRA is one of the signal transducers that may be involved in the early specialization of the embryonic lineages in pigs. To define relative distribution of the marker proteins, we used five combinations of the markers. DAB2 protein was localized in the cytoplasm and the 
transcriptional regulatory factors, SOX2, SOX17, and OCT4, were located in the nuclei of the cells. Unlike the TE marker DAB2, the ICM markers (SOX2, NANOG, and OCT4) had restricted localization in the corners of the BLs. Embryonic cells with high level of OCT4 were located in the areas with high density nuclei. Despite high cell density, $D A B 2$ protein was not condensed in the ICM region. Therefore, $D A B 2$ level may be limited in the TE cells. We also analyzed relative localization of the ICM markers. Distribution of SOX17 was scattered but restricted within the OCT4-positive cells. SOX17-positive cells were distinguished from the SOX2-positive cells. OCT4, SOX2, and NANOG play a role in the maintenance of the undifferentiated status in the human and mouse embryonic stem cells $[37,38]$. Our results suggest that OCT4, SOX2, and SOX17 are the protein markers of ICM, EPI, and Pri-Endo in pig embryos, and this interpretation is consistent with the data obtained in the human and mouse embryos.

After validation of the knockdown ability in cultured cells, the shRNA vectors were injected into the IVF embryos at the day of fertilization. Both levels of transcript and protein were decreased with anti-DAB2 shRNAs in 4-cell embryos, $D A B 2$ protein level of $D A B 2$ was low in shRNA injected morula. The developmental competency of the embryos was not influenced by the injection of the vectors. Injection of the shRNA did not cause reduction in the levels of the TE marker transcripts (CDX2 and GATA3) including DAB2 levels in the BLs. The transcriptional levels of HNF4A (an ICM marker) and PDGFRA (a Pri-Endo marker) were significantly increased in the shRNA-injected BLs. These markers may be more sensitive to $D A B 2$ than the other marker genes. Another possibility explaining this result is that the low level of $D A B 2$ in the earlier stage prior to day 5 leads to overexpression of HNF4A and PDGFRA on days 5 and 7. The other ICM and Pri-Endo marker genes showed an increasing trend; however, significant differences were not detected. The markers of ICM and Pri-Endo are the counterparts of TE and were upregulated without significant reduction in the levels of the DAB2 gene. $D A B 2$ expression level was high during the early BL stage; hence, the lineage markers were quantified on day 5 of embryo culture. PDGFRA was the only tested marker whose expression was significantly higher in the shRNA-injected BL compared with that in the control. HNF4A is a well-known marker of definitive endoderm [39]. However, additional studies on the role of HNF4A in the early embryo are required to explain our results. PDGF signaling is important for the establishment of Pri-Endo $[35,36]$. To confirm whether embryonic $D A B 2$ utilizes the $\mathrm{WNT} / \beta$-catenin singling pathway as a downstream signaling mechanism, expression levels of AXIN2 and TCF3, target genes of the WNT/ $\beta$-catenin singling, were measured [40]. The levels of both genes were not influenced by shRNAs. Thus, DAB2 action may involve another pathway of the early embryo. In mouse studies, the dab2 gene plays diverse roles in embryonic development [41]. RNA-seq of the DAB2-controlled embryos is required to confirm the exact embryonic pathway of $D A B 2$. The level of the $D A B 2$ protein was reduced by shRNAs; however, the differences were not significant. This result is consistent with the data of the mRNA levels in the BL. The vectors expressing shRNA were inefficient in suppressing the expression of $D A B 2$. Transcription of the plasmid vectors is getting progressively lower concomitant to the progress of the embryonic stages [42]; hence, the downregulation effect of DAB2 may be weak in the BLs on days 5 and 7. Knockout of $d a b 2$ is embryonically lethal in mice; thus, this gene certainly has an important role in embryonic development [43]. In single cell-based RNA studies, the quantity of $D A B 2$ was relatively high in the porcine TE cells $[20,21]$. Thus, we hypothesized that porcine DAB2 plays an important role in embryonic development and inhibition of $D A B 2$ can be critical for lineage specialization. Only with the reduction of $D A B 2$ in the early embryonic stages, some marker genes for EPI and Pri-Endo were increased in the blastocyst stages.

In conclusion, we confirmed stage-specific expression patterns of the marker transcripts and defined distribution of the marker proteins in pig embryos. Our protocol for immunocytochemistry can be especially helpful in the analysis of the responses of embryonic lineages under various experimental conditions. Additionally, we examined the effect of anti-DAB2 shRNAs on the lineage marker genes. HNF4A and PDGFRA, which are the ICM- and Pri-Endo-specific genes, respectively, were upregulated 
by shRNA-DAB2. We hope that our results are useful for investigation of the specialization of the embryonic lineages in pigs and may to fill the gap between the human and mouse studies.

\section{Materials and Methods}

The care and experimental use of pigs and mice were approved by the Institute of Laboratory Animal Resources, Seoul National University (SNU-140328-2). Unless otherwise stated, all chemicals were obtained from Sigma-Aldrich Corp. (St. Louis, MO, USA).

\subsection{In Vitro Production of Fertilized Embryos}

The ovaries of the prepubertal gilts were obtained from a local slaughterhouse (Anyang-si, Gyeonggi-do, Korea) and transferred to the laboratory in warm saline. Cumulus-oocyte complexes (COCs) were collected by aspirating 3- to 7-mm follicles of the prepubertal gilts with a 10-mL syringe and an 18-gauge needle. COCs with compact multiple layers (class $A_{1}$ and $A_{2}$ [44]) of the cumulus cells and fine cytoplasm were collected from the aspirated porcine and allowed to maturate for $44 \mathrm{~h}$ in the tissue culture medium 199 (Gibco, Grand Island, NY, USA) supplemented with 10\% follicular fluid, L-cysteine $(0.1 \mathrm{mg} / \mathrm{mL})$, sodium pyruvate $(44 \mathrm{ng} / \mathrm{mL})$, epidermal growth factor $(10 \mathrm{ng} / \mathrm{mL})$, insulin $(1 \mathrm{mg} / \mathrm{mL})$, and kanamycin $(75 \mu \mathrm{g} / \mathrm{mL})$ at $39^{\circ} \mathrm{C}$. The COCs were matured with $10 \mathrm{IU} / \mathrm{mL}$ of gonadotropin hormone, pregnant mare serum gonadotropin (Lee Biosolutions, Maryland Heights, $\mathrm{MO}, \mathrm{USA}$ ), and human chorionic gonadotropin for the first $22 \mathrm{~h}$. After the maturation, cumulus cells were removed from the oocytes with hyaluronidase. Class II oocytes were selected for further experiments [45]. Fresh semen with high viability and motility was delivered every week from Darby Genetics Inc. (Anseong, Gyeonggi-do, Korea). Sperm was washed twice with $0.1 \%$ bovine serum albumin (BSA) supplemented with Dulbecco's phosphate buffered saline (DPBS) at $1400 \mathrm{rpm}$ for $3 \mathrm{~min}$. Washed sperm was coincubated with the matured oocytes in droplets of a modified Tris-buffered medium (mTBM) and covered with mineral oil for $6 \mathrm{~h}$ (Abeydeera and Day, 1997). Each drop contained $50 \mu \mathrm{L}$ total medium, 20-25 oocytes, and $2 \times 10^{5} / \mathrm{mL}$ of sperm. mTBM was composed of $113.1 \mathrm{mM}$ sodium chloride, $3 \mathrm{mM}$ potassium chloride, $7.5 \mathrm{mM}$ calcium chloride, $20 \mathrm{mM}$ Trizma ${ }^{\circledR}$ base, $11 \mathrm{mM}$ glucose, $5 \mathrm{mM}$ pyruvate, $1 \mathrm{mM}$ caffeine, and $0.8 \%$ BSA. After this process, the eggs were incubated in $5 \% \mathrm{CO}_{2}$ and $5 \% \mathrm{O}_{2}$ at $39{ }^{\circ} \mathrm{C}$ in $20 \mu \mathrm{L}$ of the porcine zygote medium 3 [46]. The cleavage rate was measured on day 2 after the insemination.

\subsection{RNA Extraction and Quantitative PCR}

Embryonic RNA was extracted by an Arcturus ${ }^{\circledR}$ PicoPure ${ }^{\circledR}$ RNA isolation kit (Applied Biosystems, Foster City, California, USA) according to the standard protocol. cDNA was synthesized from the total RNA of a single embryo with a high-capacity RNA-to-cDNA kit (Applied Biosystems, USA) according to the standard protocol. The levels of the transcripts were normalized to the GAPDH expression level. The list of primers is shown in Table A1.

\subsection{Immunocytochemistry of Embryos}

Embryos were washed twice with DPBS supplemented with $0.1 \%$ BSA and fixed with $4 \%$ paraformaldehyde in DPBS at room temperature (RT) for $15 \mathrm{~min}$. Fixed embryos were permeabilized using $0.2 \%$ Tween-20 and $0.2 \%$ Triton X-100 in DPBS at RT for 15 min and then blocked with $10 \%$ donkey serum in DPBS at RT for $1 \mathrm{~h}$. Samples were stained with anti-SOX2, DAB2, NANOG, OCT4, and SOX17 in DPBS containing $10 \%$ donkey serum at $4{ }^{\circ} \mathrm{C}$ overnight. After washing three times in the washing solution (DPBS with $0.2 \%$ Tween-20 and 1\% BSA for $10 \mathrm{~min}$ ), the embryos were incubated with donkey anti-rabbit Alexa594 or goat anti-rabbit Alexa488 (Invitrogen, Carlsbad, California, USA) in DPBS with $10 \%$ donkey serum at RT for $1 \mathrm{~h}$. For double staining, samples were stained again with the corresponding primary and secondary antibodies. Steps were the same but primary antibody treatment was conducted at RT for $2 \mathrm{~h}$. All samples were washed three times with the washing solution after the secondary antibody treatment. Immunostained embryos were mounted on a slide glass with 
Prolong gold with DAPI (Invitrogen) and cured for at least $24 \mathrm{~h}$. The list of antibodies is shown in Table A2. The imaging tool of micromanipulator was used to take the fluorescence and bright-field images. We used the ImageJ program for image processing and surface plots (monochrome images were used to produce the surface plot images).

\subsection{Production of shRNA-Expressing Vectors and DAB2 Gene Expression Vector}

The shRNA targeting sequences within the DAB2 coding region (Gene ID number; 100519746) were identified using an online tool (https://www.thermofisher.com). The shRNA sequences were aligned to the whole transcriptome of the pig through the BLAST program (https://blast.ncbi.nlm.nih.gov/Blast.cgi). Three sequences with an off-target low level were used to produce the DNA constructs containing the targeting sequence and a nine-nucleotide loop. Pairs of the synthesized oligonucleotides were dimerized by slow cooling from 95 to $4{ }^{\circ} \mathrm{C}$ and inserted into the U6 cloning site of the pENTR.hU6hH1 plasmid vector. The Dab2 coding region sequence was synthesized and inserted into the multiple cloning site of the pcDNA3-EGFP vector. All vectors were verified by nucleotide sequencing.

\subsection{Culture of Porcine Fetal Fibroblasts and Plasmid Transfection}

Basic cell culture and lipofection were carried out as described in our previous report [47]. Briefly, the vectors containing shRNA and expressing $D A B 2$ gene at a 1:1 ratio were introduced into $\mathrm{pFF}$ using Lipofectamine 3000 reagent (Thermo Fisher Scientific, Waltham, MA, USA). We replaced the culture medium with fresh Dulbecco's modified Eagle's medium $24 \mathrm{~h}$ after from lipofection and the cells were subsequently cultured for 2 days. The total RNA of the transfected pFFs was isolated with TRIzol reagent (Invitrogen, USA) according to the manufacturer's instructions. cDNA was synthesized with the same kit and protocol as described above. The levels of the transcripts were normalized versus the $A C T B$ expression levels.

\subsection{Microinjection of Plasmid Vectors into IVF Embryos}

Microinjection procedure was conducted with a micromanipulator (Eclipse TE2000, Nikon, Tokyo, Japan) with the holding and injection pipettes. We used Femtotip II (Eppendorf, Hamburg, Germany) as an injection pipette. The concentration of the shRNA vectors (1:1 ratio of sh-DAB2-1 and sh-DAB2-2) was $300 \mathrm{ng} / \mu \mathrm{L}$. To increase the efficiency of plasmid transfer, Lipofectamine stem transfection reagent (Invitrogen) was used according to the manufacturer's manual. Plasmid vectors with Lipofectamine $(50 \mathrm{ng} / \mu \mathrm{L})$ were loaded and injected into the fertilized eggs on the day of IVF.

\subsection{Statistical Analysis}

Statistical analysis of the data was performed using GraphPad Prism software (version 5.01; San Diego, CA, USA). Significant differences in the experimental groups were determined by one-way analysis of variance followed by Tukey's multiple comparison test. A $p$-value $<0.05$ was considered significant. Data are presented as the mean \pm standard error.

Author Contributions: Conceptualization, J.-N.O. and C.-K.L.; methodology, J.-N.O.; formal analysis, J.-N.O.; investigation, J.-N.O., M.L., and G.C.C.; data curation, J.-N.O.; writing-original draft preparation, J.-N.O.; writing-review and editing, M.L., G.C.C., D.-K.L., K.-H.C., S.-H.K., J.J., and C.-K.L.; visualization, J.-N.O.; supervision, D.-K.L., K.-H.C., and C.-K.L.; project administration, J.-N.O.; funding acquisition, K.-H.C. and C.-K.L. All authors have read and agreed to the published version of the manuscript.

Funding: This work was supported by the BK21 Plus Program and the Korea Institute of Planning and Evaluation for Technology in Food, Agriculture, Forestry, and Fisheries (IPET) through the Development of High Value-Added Food Technology Program funded by the Ministry of Agriculture, Food and Rural Affairs (MAFRA; 118042-03-1-HD020), and This work was supported by the BK21 Plus Program and the National Research Foundation of Korea (NRF) Grant funded by the Korea government (NRF-2019R1C1C1004514).

Conflicts of Interest: The authors declare no conflict of interest. The funders had no role in the design of the study; in the collection, analyses, or interpretation of data; in the writing of the manuscript, or in the decision to publish the results. 


\section{Abbreviations}

$\begin{array}{ll}\text { ICM } & \text { Inner cell mass } \\ \text { TE } & \text { Trophectoderm } \\ \text { EPI } & \text { Epiblast } \\ \text { Pri-Endo } & \text { Primitive endoderm } \\ \text { BL } & \text { Blastocyst } \\ \text { qPCR } & \text { Quantitative PCR } \\ \text { IVF } & \text { In vitro fertilized } \\ \text { pFF } & \text { Porcine fetal fibroblasts } \\ \text { COCs } & \text { Cumulus-oocyte complexes } \\ \text { BSA } & \text { Bovine serum albumin } \\ \text { DPBS } & \text { Dulbecco's Phosphate Buffered Saline } \\ \text { mTBM } & \text { Modified Tris-buffered medium } \\ \text { RT } & \text { Room temperature }\end{array}$

\section{Appendix A}

Table A1. Oligonucleotide sequences used in shRNA cloning and quantitative PCR.

\begin{tabular}{|c|c|c|c|c|}
\hline \multicolumn{2}{|c|}{ Name of oligonucleotide } & \multicolumn{3}{|c|}{ Sequence } \\
\hline \multirow{2}{*}{$\begin{array}{c}\text { Anti-Dab2 } \\
\text { shRNA-1 }\end{array}$} & Forward & \multicolumn{3}{|c|}{ ccggtGGCAGCAATTTGACCAGATCTTTCAAGAGAAGATCTGGTCAAATTGCTGCCTTTTTg } \\
\hline & Reverse & \multicolumn{3}{|c|}{ aattcAAAAAGGCAGCAATTTGACCAGATCTTCTCTTGAAAGATCTGGTCAAATTGCTGCCa } \\
\hline \multirow{2}{*}{$\begin{array}{l}\text { Anti-Dab2 } \\
\text { shRNA-2 }\end{array}$} & Forward & \multicolumn{3}{|c|}{ ccggtGATTACTTTGGGCAGCAATTTTTCAAGAGAAAATTGCTGCCCAAAGTAATCTTTTTg } \\
\hline & Reverse & \multicolumn{3}{|c|}{ aattcAAAAAGATTACTTTGGGCAGCAATTTTCTCTTGAAAAATTGCTGCCCAAAGTAATCa } \\
\hline \multirow{2}{*}{$\begin{array}{l}\text { Anti-Dab2 } \\
\text { shRNA-3 }\end{array}$} & Forward & \multicolumn{3}{|c|}{ ccggtGCAATTTGACCAGATCTCTAATTCAAGAGATTAGAGATCTGGTCAAATTGCTTTTTg } \\
\hline & Reverse & \multicolumn{3}{|c|}{ aattcAAAAAGCAATTTGACCAGATCTCTAATCTCTTGAATTAGAGATCTGGTCAAATTGCa } \\
\hline \multicolumn{2}{|c|}{ Primers for qPCR } & Sequence & Annealing $\operatorname{Tm}\left({ }^{\circ} \mathrm{C}\right)$ & Product size (bp) \\
\hline \multirow{2}{*}{$D A B 2$} & Forward & TGGGAGTGAGGCCCTAATGA & 58 & \multirow{2}{*}{$111 \mathrm{bp}$} \\
\hline & Reverse & GGACTACTTAGGTCGGGAGGT & 58 & \\
\hline \multirow{2}{*}{ GATA3 } & Forward & GCGGGCTCTACCACAAAA & 61 & \multirow{2}{*}{$141 \mathrm{bp}$} \\
\hline & Reverse & CGTTGGCATTTCTTCTCCA & 61 & \\
\hline \multirow{2}{*}{$C D X 2$} & Forward & CAGCGGCGGAACCTGTG & 63 & \multirow{2}{*}{$92 \mathrm{bp}$} \\
\hline & Reverse & ACTCGGTATTTGTCTTTCGTCCTG & 63 & \\
\hline \multirow{2}{*}{ OCT4A } & Forward & GCTGGAGCCGAACCCCGAGG & 68 & \multirow{2}{*}{$150 \mathrm{bp}$} \\
\hline & Reverse & CACCTTCCCAAAGAGAACCCCCAAA & 68 & \\
\hline \multirow{2}{*}{ SOX2 } & Forward & CGGCGGTGGCAACTCTAC & 64 & \multirow{2}{*}{$100 \mathrm{bp}$} \\
\hline & Reverse & TCGGGACCACACCATGAAAG & 64 & \\
\hline \multirow{2}{*}{ NANOG } & Forward & CATCTGCTGAGACCCTCGAC & 60 & \multirow{2}{*}{$195 \mathrm{bp}$} \\
\hline & Reverse & GGGTCTGCGAGAACACAGTT & 60 & \\
\hline \multirow{2}{*}{ HNF4a } & Forward & GCTTCTTTCGGAGGAGTGTG & 58 & \multirow{2}{*}{$183 \mathrm{bp}$} \\
\hline & Reverse & TTGACCTGCGAGTGCTGAT & 58 & \\
\hline \multirow{2}{*}{ PDGFA } & Forward & CAGCGTGGTCTTTGTTCTCC & 60 & \multirow{2}{*}{$189 \mathrm{bp}$} \\
\hline & Reverse & TGTTTCGTGGTTCTGTTTGC & 60 & \\
\hline \multirow{2}{*}{ PDGFRA } & Forward & GGTCACCTGTGCCGTCTTTA & 59 & \multirow{2}{*}{$115 \mathrm{bp}$} \\
\hline & Reverse & TTTGATGGACGGGACCTTGG & 59 & \\
\hline \multirow{2}{*}{ GAPDH } & Forward & TGCTCCTCCCCGTTCGAC & 60 & \multirow[t]{2}{*}{$100 \mathrm{bp}$} \\
\hline & Reverse & ATGCGGCCAAATCCGTTC & 60 & \\
\hline$A C T B$ & Forward & GTGGACATCAGGAAGGACCTCTA & 63 & $131 \mathrm{bp}$ \\
\hline & Reverse & ATGATCTTGATCTTCATGGTGCT & 63 & \\
\hline
\end{tabular}


Table A2. List of antibodies.

\begin{tabular}{|c|c|c|c|c|c|}
\hline $\begin{array}{c}\text { Primary } \\
\text { Antibodies }\end{array}$ & Target & Host & Company & $\begin{array}{l}\text { Catalog } \\
\text { Number }\end{array}$ & $\begin{array}{l}\text { Concentration } \\
\text { of Antibody }\end{array}$ \\
\hline & SOX2 & Rabbit & Millipore & AB5603 & $5 \mu \mathrm{g} / \mathrm{mL}$ \\
\hline & DAB2 & Goat & R\&D systems & AF8064 & $2 \mu \mathrm{g} / \mathrm{mL}$ \\
\hline & NANOG & Rabbit & Peprotech & 500-P236 & $1 \mu \mathrm{g} / \mathrm{mL}$ \\
\hline & OCT4 & Rabbit & SantaCruz & sc-9081 & $1 \mu \mathrm{g} / \mathrm{mL}$ \\
\hline & SOX17 & Goat & R\&D systems & AF1924 & $1 \mu \mathrm{g} / \mathrm{mL}$ \\
\hline \multirow[t]{3}{*}{$\begin{array}{l}\text { Secondary } \\
\text { Antibodies }\end{array}$} & Fluorescent dye & Target/Host & Company & $\begin{array}{l}\text { Catalog } \\
\text { Number }\end{array}$ & $\begin{array}{c}\text { Concentration } \\
\text { of Antibody }\end{array}$ \\
\hline & Alexa594 & Rabbit/Donkey & Invitrogen & A-21207 & $1: 5000$ \\
\hline & Alexa488 & Goat/Donkey & Invitrogen & A-11055 & $1: 5000$ \\
\hline
\end{tabular}

\section{References}

1. Saini, D.; Yamanaka, Y. Cell Polarity-Dependent Regulation of Cell Allocation and the First Lineage Specification in the Preimplantation Mouse Embryo. Curr. Top. Dev. Biol. 2018, 128, 11-35. [PubMed]

2. Rossant, J. Genetic Control of Early Cell Lineages in the Mammalian Embryo. Ann. Rev. Genet. 2018, 52, 185-201. [CrossRef] [PubMed]

3. Alberio, R. Transcriptional and epigenetic control of cell fate decisions in early embryos. Reprod. Fertil. Dev. 2017, 30, 73-84. [CrossRef] [PubMed]

4. Baker, C.L.; Pera, M.F. Capturing Totipotent Stem Cells. Cell Stem Cell 2018, 22, 25-34. [CrossRef]

5. Houston, D.W. Vertebrate Axial Patterning: From Egg to Asymmetry. Adv. Exp. Med. Biol. 2017, 953, $209-306$.

6. Leung, C.Y.; Zernicka-Goetz, M. Mapping the journey from totipotency to lineage specification in the mouse embryo. Curr. Opin. Genet. Dev. 2015, 34,71-76. [CrossRef]

7. Chen, Q.; Shi, J.; Tao, Y.; Zernicka-Goetz, M. Tracing the origin of heterogeneity and symmetry breaking in the early mammalian embryo. Nat. Commun. 2018, 9, 1819. [CrossRef]

8. Johnson, M.H. From mouse egg to mouse embryo: Polarities, axes, and tissues. Annu. Rev. Cell Dev. Biol. 2009, 25, 483-512. [CrossRef]

9. Guo, G.; Huss, M.; Tong, G.Q.; Wang, C.; Li Sun, L.; Clarke, N.D.; Robson, P. Resolution of cell fate decisions revealed by single-cell gene expression analysis from zygote to blastocyst. Dev. Cell 2010, 18, 675-685. [CrossRef]

10. Lou, X.; Kang, M.; Xenopoulos, P.; Munoz-Descalzo, S.; Hadjantonakis, A.K. A rapid and efficient 2D/3D nuclear segmentation method for analysis of early mouse embryo and stem cell image data. Stem Cell Rep. 2014, 2, 382-397. [CrossRef]

11. Biase, F.H.; Cao, X.; Zhong, S. Cell fate inclination within 2-cell and 4-cell mouse embryos revealed by single-cell RNA sequencing. Genome Res. 2014, 24, 1787-1796. [CrossRef] [PubMed]

12. Shi, J.; Chen, Q.; Li, X.; Zheng, X.; Zhang, Y.; Qiao, J.; Tang, F.; Tao, Y.; Zhou, Q.; Duan, E. Dynamic transcriptional symmetry-breaking in pre-implantation mammalian embryo development revealed by single-cell RNA-seq. Development 2015, 142, 3468-3477. [CrossRef] [PubMed]

13. Petropoulos, S.; Edsgard, D.; Reinius, B.; Deng, Q.; Panula, S.P.; Codeluppi, S.; Plaza Reyes, A.; Linnarsson, S.; Sandberg, R.; Lanner, F. Single-Cell RNA-Seq Reveals Lineage and X Chromosome Dynamics in Human Preimplantation Embryos. Cell 2016, 165, 1012-1026. [CrossRef] [PubMed]

14. Blakeley, P.; Fogarty, N.M.; Del Valle, I.; Wamaitha, S.E.; Hu, T.X.; Elder, K.; Snell, P.; Christie, L.; Robson, P.; Niakan, K.K. Defining the three cell lineages of the human blastocyst by single-cell RNA-seq. Development 2015, 142, 3613. [CrossRef] [PubMed]

15. Zhang, Y.; Xiang, Y.; Yin, Q.; Du, Z.; Peng, X.; Wang, Q.; Fidalgo, M.; Xia, W.; Li, Y.; Zhao, Z.A.; et al. Dynamic epigenomic landscapes during early lineage specification in mouse embryos. Nat. Genet. 2018, 50, 96-105. [CrossRef] [PubMed]

16. Zhu, P.; Guo, H.; Ren, Y.; Hou, Y.; Dong, J.; Li, R.; Lian, Y.; Fan, X.; Hu, B.; Gao, Y.; et al. Single-cell DNA methylome sequencing of human preimplantation embryos. Nat. Genet. 2018, 50, 12-19. [CrossRef] [PubMed] 
17. Choi, K.-H.; Lee, C.-K. Pig Pluripotent Stem Cells as a Candidate for Biomedical Application. J. Anim. Reprod. Biotechnol. 2019, 34, 8. [CrossRef]

18. Han, N.R.; Baek, S.; Lee, Y.; Lee, J.; Yun, J.I.; Lee, E.; Lee, S.T. Effects of in vitro Culture Period of Reconstructed Embryos and Genetic Background of Feeder Cells on Establishment of Embryonic Stem Cells Derived from Somatic Cell Nuclear Transfer Blastocysts in Pigs. J. Anim. Reprod. Biotechnol. 2020, 35, 8. [CrossRef]

19. Lavagi, I.; Krebs, S.; Simmet, K.; Beck, A.; Zakhartchenko, V.; Wolf, E.; Blum, H. Single-cell RNA sequencing reveals developmental heterogeneity of blastomeres during major genome activation in bovine embryos. Sci. Rep. 2018, 8, 4071. [CrossRef]

20. Wei, Q.; Li, R.; Zhong, L.; Mu, H.; Zhang, S.; Yue, L.; Xiang, J.; Li, E.; Zhi, M.; Cao, S.; et al. Lineage specification revealed by single-cell gene expression analysis in porcine preimplantation embryos. Biol. Reprod. 2018, 99, 283-292. [CrossRef]

21. Ramos-Ibeas, P.; Sang, F.; Zhu, Q.; Tang WW, C.; Withey, S.; Klisch, D.; Wood, L.; Loose, M.; Surani, M.A.; Alberio, R. Pluripotency and $\mathrm{X}$ chromosome dynamics revealed in pig pre-gastrulating embryos by single cell analysis. Nat. Commun. 2019, 10, 500. [CrossRef] [PubMed]

22. Kong, Q.; Yang, X.; Zhang, H.; Liu, S.; Zhao, J.; Zhang, J.; Weng, X.; Jin, J.; Liu, Z. Lineage specification and pluripotency revealed by transcriptome analysis from oocyte to blastocyst in pig. Faseb J. 2020, 34, 691-705. [CrossRef] [PubMed]

23. Arnold, S.J.; Robertson, E.J. Making a commitment: Cell lineage allocation and axis patterning in the early mouse embryo. Nat. Rev. Mol. Cell Biol. 2009, 10, 91-103. [CrossRef]

24. Lanner, F. Lineage specification in the early mouse embryo. Exp. Cell Res. 2014, 321, 32-39. [CrossRef] [PubMed]

25. Ralston, A.; Rossant, J. CDX2 acts downstream of cell polarization to cell-autonomously promote trophectoderm fate in the early mouse embryo. Dev. Biol. 2008, 313, 614-629. [CrossRef] [PubMed]

26. Strumpf, D.; Mao, C.A.; Yamanaka, Y.; Ralston, A.; Chawengsaksophak, K.; Beck, F.; Rossant, J. CDX2 is required for correct cell fate specification and differentiation of trophectoderm in the mouse blastocyst. Development 2005, 132, 2093-2102. [CrossRef] [PubMed]

27. Bou, G.; Liu, S.; Sun, M.; Zhu, J.; Xue, B.; Guo, J.; Zhao, Y.; Qu, B.; Weng, X.; Wei, Y.; et al. CDX2 is essential for cell proliferation and polarity in porcine blastocysts. Development 2017, 144, 1296-1306. [CrossRef]

28. Berg, D.K.; Smith, C.S.; Pearton, D.J.; Wells, D.N.; Broadhurst, R.; Donnison, M.; Pfeffer, P.L. Trophectoderm lineage determination in cattle. Dev. Cell 2011, 20, 244-255. [CrossRef]

29. Chazaud, C.; Yamanaka, Y. Lineage specification in the mouse preimplantation embryo. Development 2016, 143, 1063-1074. [CrossRef]

30. Kuijk, E.W.; Du Puy, L.; Van Tol, H.T.; Oei, C.H.; Haagsman, H.P.; Colenbrander, B.; Roelen, B.A. Differences in early lineage segregation between mammals. Dev. Dyn. 2008, 237, 918-927. [CrossRef]

31. Han, N.R.; Baek, S.; Lee, Y.; Lee, J.; Yun, J.I.; Lee, E.; Lee, S.T. Establishment of In-Vitro Culture System for Enhancing Production of Somatic Cell Nuclear Transfer (SCNT) Blastocysts with High Performance in the Colony Formation and Formation of Colonies Derived from SCNT Blastocysts in Pigs. J. Anim. Reprod. Biotechnol. 2019, 34, 9. [CrossRef]

32. Papaioannou, V.E.; Ebert, K.M. The preimplantation pig embryo: Cell number and allocation to trophectoderm and inner cell mass of the blastocyst in vivo and in vitro. Development 1988, 102, 793-803. [PubMed]

33. Pomar, F.J.; Teerds, K.J.; Kidson, A.; Colenbrander, B.; Tharasanit, T.; Aguilar, B.; Roelen, B.A. Differences in the incidence of apoptosis between in vivo and in vitro produced blastocysts of farm animal species: A comparative study. Theriogenology 2005, 63, 2254-2268. [CrossRef]

34. Kashyap, V.; Rezende, N.C.; Scotland, K.B.; Shaffer, S.M.; Persson, J.L.; Gudas, L.J.; Mongan, N.P. Regulation of stem cell pluripotency and differentiation involves a mutual regulatory circuit of the NANOG, OCT4, and SOX2 pluripotency transcription factors with polycomb repressive complexes and stem cell microRNAs. Stem Cells Dev. 2009, 18, 1093-1108. [CrossRef] [PubMed]

35. Artus, J.; Kang, M.; Cohen-Tannoudji, M.; Hadjantonakis, A.K. PDGF signaling is required for primitive endoderm cell survival in the inner cell mass of the mouse blastocyst. Stem Cells 2013, 31, 1932-1941. [CrossRef]

36. Artus, J.; Panthier, J.J.; Hadjantonakis, A.K. A role for PDGF signaling in expansion of the extra-embryonic endoderm lineage of the mouse blastocyst. Development 2010, 137, 3361-3372. [CrossRef] [PubMed] 
37. Boyer, L.A.; Lee, T.I.; Cole, M.F.; Johnstone, S.E.; Levine, S.S.; Zucker, J.P.; Guenther, M.G.; Kumar, R.M.; Murray, H.L.; Jenner, R.G.; et al. Core transcriptional regulatory circuitry in human embryonic stem cells. Cell 2005, 122, 947-956. [CrossRef]

38. Boyer, L.A.; Plath, K.; Zeitlinger, J.; Brambrink, T.; Medeiros, L.A.; Lee, T.I.; Levine, S.S.; Wernig, M.; Tajonar, A.; Ray, M.K.; et al. Polycomb complexes repress developmental regulators in murine embryonic stem cells. Nature 2006, 441, 349-353. [CrossRef]

39. Liu, Z.; Scannell, D.R.; Eisen, M.B.; Tjian, R. Control of embryonic stem cell lineage commitment by core promoter factor, TAF3. Cell 2011, 146, 720-731. [CrossRef]

40. Hofsteen, P.; Robitaille, A.M.; Chapman, D.P.; Moon, R.T.; Murry, C.E. Quantitative proteomics identify $D A B 2$ as a cardiac developmental regulator that inhibits WNT/beta-catenin signaling. Proc. Natl. Acad. Sci. USA 2016, 113, 1002-1007. [CrossRef]

41. Moore, R.; Cai, K.Q.; Tao, W.; Smith, E.R.; Xu, X.X. Differential requirement for Dab2 in the development of embryonic and extra-embryonic tissues. BMC Dev. Biol. 2013, 13, 39. [CrossRef] [PubMed]

42. Wang, J.; Wang, L.; Feng, G.; Wang, Y.; Li, Y.; Li, X.; Liu, C.; Jiao, G.; Huang, C.; Shi, J.; et al. Asymmetric Expression of LincGET Biases Cell Fate in Two-Cell Mouse Embryos. Cell 2018, 175, 1887-1901.e18. [CrossRef] [PubMed]

43. Yang, D.H.; Smith, E.R.; Roland, I.H.; Sheng, Z.; He, J.; Martin, W.D.; Hamilton, T.C.; Lambeth, J.D.; Xu, X.X. Disabled-2 is essential for endodermal cell positioning and structure formation during mouse embryogenesis. Dev. Biol. 2002, 251, 27-44. [CrossRef] [PubMed]

44. Alvarez, G.M.; Dalvit, G.C.; Achi, M.V.; Miguez, M.S.; Cetica, P.D. Immature oocyte quality and maturational competence of porcine cumulus-oocyte complexes subpopulations. Biocell 2009, 33, 167-177. [CrossRef] [PubMed]

45. Hiraga, K.; Hoshino, Y.; Tanemura, K.; Sato, E. Selection of in vitro-matured porcine oocytes based on localization patterns of lipid droplets to evaluate developmental competence. J. Reprod. Dev. 2013, 59, 405-408. [CrossRef]

46. Yoshioka, K.; Suzuki, C.; Tanaka, A.; Anas, I.M.; Iwamura, S. Birth of piglets derived from porcine zygotes cultured in a chemically defined medium. Biol. Reprod. 2002, 66, 112-119. [CrossRef]

47. Oh, J.N.; Choi, K.H.; Lee, C.K. Multi-resistance strategy for viral diseases and in vitro short hairpin RNA verification method in pigs. Asian-Australas J. Anim. Sci. 2018, 31, 489-498. [CrossRef] 